\title{
Lasting Changes on Etextbook Acquisitions for Textbook Affordability due to COVID-19
}

\author{
Justin M. White, The University of Texas Rio Grande Valley
}

\begin{abstract}
When the University of Texas Rio Grande Valley University Library started purchasing etextbooks for required courses in 2018, we were one of the few in the UT System who had an explicit program. Now, it's becoming a more common practice for libraries to put funds usually reserved for course reserves or other faculty requests into ebooks. As COVID began to shut down our physical operations we began to receive a large influx of etextbook requests from faculty. Luckily, the library had a student savings tracking process in place for required etextbook purchases, and a fund designated for these purchases. The strong relationship between Collection Development and Scholarly Communications prior to the influx of new requests made adapting to this influx relatively orderly.

\section{KEYWORDS}

textbook affordability, etextbooks, collection development, quality education
\end{abstract}

\section{SUGGESTED CITATION}

White, J. M. (2022). Lasting changes on etextbook acquisitions for textbook affordability due to COVID-19 [Column]. Journal of New Librarianship, 7(1), 88-94.

https://doi.org/10.33011/newlibs/11/10

This is an Open Access article distributed under the terms of the Creative Commons Attribution 4.0 International License (http://creativecommons.org/licenses/by/4.0), which permits unrestricted use, distribution, and reproduction in any medium, provided the original work is properly cited. 
At the University of Texas Rio Grande Valley (UTRGV), the Library's Scholarly Communications Department started a program in 2018 for textbook affordability that included the library purchase of unlimited concurrent user licenses (UCUL) for required course textbooks. UCULs are ebook licenses that allow an unlimited number of users to access an ebook at once, which is necessary for replacing a required textbook in a course that may have dozens of students trying to access the text at any one time. This was given its own funding code (TXBAF), an initial budget of $\$ 10,000$, and was expected to expand within the next year or so. There was, until COVID, an institutional slowness about ebook purchasing, both within the library and from faculty. Luckily, having already created a funding code for UCUL ebooks, we were able to track new purchases and estimate student savings once COVID required us to increase our UCUL ebook purchasing. Student savings were estimated using the previous cost of the textbook, multiplied by enrollment, and subtracting the library license cost. This created a "return on investment" estimate for the UCUL etextbook purchasing program.

\section{First Summer of COVID}

The library ended all physical material loaning in Spring 2020 and moved most staff to remote work. This meant that all physical course reserves were unavailable to faculty and students. While the library took part in the Hathi Trust Emergency Temporary Access Service, there was still a significant lack of ebooks previously on course reserve. Once we shut down after COVID-19 in Spring, and faculty realized their summer courses were going to be online, we greatly ramped up the program, which required several fundamental changes in the way we had been acquiring materials and how library departments were working together. If it hadn't been for the previous understanding about what kinds of licenses were needed for required textbooks, who was monitoring student savings made by UCUL purchases, and what funding code was to be used, this transition might have been much more chaotic.

Despite a great deal of momentum on textbook affordability through Open Educational Resources (OER) and library licensed ebooks, the majority of the requests flooded into the library's Collection Development department via our purchase request forms and course reserve request forms. Collection Development and Scholarly Communications had to work together to identify the best solution for what faculty wanted, such as a course reserve, an unlimited concurrent user licensed ebook, or just an expansion of the collection. At time of publication, the Scholarly Communications Department has records of contact with 411 faculty members, which is roughly a third of the faculty at UTRGV.

Eventually we halted almost all physical book purchases and greatly expanded the textbook affordability (TXBAF) fund, and developed a new collection development policy section focused on etextbooks. 


\section{New Workflow}

Over the last year, the Collection Development and Scholarly Communications Departments have developed new request forms, new workflows, and new policies that simplify how requests come in. The new forms asked for information that helped Collection Development route requests based on faculty needs, such as if a book was a required textbook or a general collection suggestion. This helped route the requests to the right department to follow up with the faculty making the request, since the etextbook might not be available and OER might be suggested instead.

\section{New Faculty Request Forms}

Previously, the library had two material request forms. The first is the one-time purchases form, which faculty/staff/students could use to request books, DVDs, or other nonsubscription materials. The second was a faculty-only form for course reserves. The vagueness of the forms required a lot of back and forth with faculty, especially when UCUL licenses got involved. We needed to know faculty intentions for the request to suggest the right license or alternative resource. Since COVID meant the library was no longer circulating physical materials for an extended time, we shifted to purchasing ebooks for all requests. Faculty requests were prioritized while staff and student requests were temporarily paused. Ebooks became the default for faculty requests due to the inability of students to access physical materials for the foreseeable future, and the library needed a way to distinguish what sort of user license we should purchase. Our previous policy had been to purchase one-user licenses (1U) for all ebook acquisitions, which are ebook licenses for one user at a time. The exception was for those specifically selected by Scholarly Communications for textbook affordability (using the TXBAF fund), which would use unlimited concurrent user licenses. We additionally adjusted the policy to favor UCUL when the cost difference between one user or three user licenses and unlimited licenses was small.

The new request form for one time purchases (books, DVDs, or other non-subscription materials) included options near the top of the form for faculty to indicate their purpose in requesting the book. The request form included options for staff and students, though at the time those requests were still being deprioritized. The form asked faculty to indicate if a material is a required textbook, for instruction, for research, or a general collection addition request. If the book is being requested because it's a required textbook for a course the request form would be forwarded to the Scholarly Communications Librarian. The Scholarly Communications Librarian would then reach out to the faculty to explain UCUL licenses for ebooks and how this can help with affordability before moving forward to use the TXBAF funds. The library continued to have a separate course reserves form, but also added a field to indicate if a faculty member was ordering copies to give students access, in which case the request would be submitted to the same workflow as above. 


\section{Bringing in Scholarly Communications: What if We Can't Buy it?}

The new request forms were specifically designed to also funnel required textbook requests to Scholarly Communications. The Scholarly Communications Librarian would make the purchase if available, and if not, would serve as the first point of contact for a discussion with the faculty member about OER or other library-licensed options. All requests for items that are marked as course required materials are now forwarded to the Scholarly Communications department, where we can determine if the correct license is available. This is done through our regular selection process in GOBI. GOBI is a platform many libraries use to manage their physical book, ebook, and other physical media purchases. GOBI also allows for robust tracking via separate fund codes or secondary codes that inform us what material was selected and why. Books are filtered out by using a title search sorted by ebook availability, and then secondarily sorted by those with the UCUL option. In some circumstances, we have considered buying multiple three-user licenses $(3 \mathrm{U})$ for low enrollment graduate courses where we know from the faculty member teaching the course what the enrollment will be each semester without much fluctuation. For example, some internship courses are limited to eight or nine students due to available slots with local professionals, so we could purchase three $3 \mathrm{U}$ licenses for a book that would allow nine concurrent users for the title. However, this hasn't been put into effect for any courses at time of writing.

If the title with the correct license isn't available, the Scholarly Communications Librarian or Open Education Librarian will suggest alternatives to the faculty member, such as OER, Open Practices (OEP), a mix and match of licensed ebooks we could purchase or already own, or online free resources that are not OER. At this point, the matter would become internal to the Scholarly Communications team who would begin their process of helping faculty assess whether they could redesign their course with affordable materials. The original request would then be cancelled since the book isn't available. Either the Scholarly Communications Librarian or the Open Education Librarian (who reports to the Scholarly Communications Librarian) would approach the faculty member with their options going forward.

\section{Lasting Changes to Collection Development Policy}

With the increase in ebook purchasing, both due to the TXBAF fund and the temporary suspension of physical circulation, the Collection Development department began making revisions to the library's collection development policy. Under the old policy, librarians with collection development duties (known as "selectors") were required to make only $1 \mathrm{~L}$ license purchases to minimize cost. Selectors also had larger amounts of money to spend on collection development, which changed during 2020 to accommodate more immediate faculty requests.

The TXBAF fund was created under the old collection development policy and was the exception to the previous policy of selecting $1 \mathrm{U}$ licenses whenever possible. Because of that, it was entirely controlled by the Scholarly Communications Librarian (and later the Open 
Education Librarian). The fund was initially used to purchase required textbooks that were available with UCULs. These books were found by using bookstore data on assigned textbooks and running the ISBNs in bulk into GOBI. Each semester, the Scholarly Communications Librarian would get the required textbook data from the bookstore, run the ISBNs through GOBI, and filter for those with UCUL licenses available. Then the librarian would reach out to those faculty members with a form email, informing them their title was available for the library to purchase in a way that all students could use it without having to buy a copy themselves, and asking if the faculty member wanted to move forward with the purchase. The first semester, which was pre-COVID, interestingly enough, had the highest numbers of denials. Faculty insisted these students would either need to mark up their copy or would need to own it as a reference later in their professional practice. After COVID, these objections entirely went away. Although the list of items we can purchase is limited due to publishers refusing UCULs to libraries, and thus not a good sample size (usually only 50 or so titles), it might indicate a change in faculty perceptions of etextbooks.

The increased flow of ebook requests from faculty during the summer of 2020 meant a revision to the collection development policy was needed. The major revision relevant here was the codification of the TXBAF process into the policy. The UTRGV University Library Collection Development Policy (2020) reads:

The library does not actively purchase textbooks for classroom use unless through the textbook affordability initiative at the library. The library will on occasion purchase print textbooks when requested while keeping in mind space and limiting to one copy. The library will purchase digital textbooks through vendors that supply to libraries with the appropriate licenses. For more information, visit Statement on Textbooks in the Library Collection [https://utrgv.libguides.com/textbookstatement]. ... The Library also supports the adoption of Open Educational Resources (OER) for faculty use as primary course materials. For more information, visit https://utrgv.libguides.com/oer. (p. 3)

The Statement on Textbooks linked in the quote above is an adaptation of the University of Guelph Library's (2020) Commercial Textbooks Present Challenges in a Virtual Environment and explains the difficulties of acquiring UCUL licenses for textbooks due to publisher policies and offerings.

\section{Future Changes Ahead?}

Due to the ongoing textbook affordability work and the reliance on not just OER, but library licensed materials, the library is expecting to make future investments in tools and processes that forward the goal of overall textbook affordability. One example is piloting Leganto, a product from Ex Libris that is conducive to course design and offers a convenient platform for merging and organizing resources, including proprietary and third-party materials. Currently, funding for this pilot is off the table, but we may return to it in the near future. The 
library is also constantly building capacity for library publishing focused on OER textbooks and supplemental materials. To that end, the library may acquire a subscription to PressbooksEDU, buy a bundle of ISBNs, and budget for funding required to do typesetting and copyediting through a third party, as well as a budget for peer review. With the possibility of future COVID19 spikes, we are remaining cautious but optimistic that we would be able to continue our textbook affordability work however the Fall 2021 semester plays out. 


\section{References}

The University of Guelph Library. (2020, June 22). Commercial textbooks present challenges in a virtual environment [Library news]. https://www.lib.uoguelph.ca/news/commercialtextbooks-present-challenges-virtual-environment. Archived at https://perma.cc/M8K.5CJ7E

The University of Texas Rio Grande Valley University Library. (2020). UTRGV University Library collection development policy.

https://utrgv.libguides.com/ld.php?content id=45018019. Archived at https://perma.cc/M6YV-PCNX 